\title{
SELECTIVE PRECIPITATION OF YTTRIUM FROM MONAZITE ACID LEACH LIQUOR BY USING CARBONATES PRECIPITATION METHOD.
}

\author{
El-Awady, M. E. ; Abd-Elfatah, A. I. L. ; Abd-Elwahab, S. M. '; Mahmoud, A. H. ${ }^{*}$ and Helaly, O. S. \\ ${ }^{*}$ Nuclear Materials Authority, P. O. Box: 530 El Maadi, Cairo, Egypt. \\ ${ }^{\dagger}$ Faculty of Science, Ain-Shams University, Cairo, Egypt.
}

\begin{abstract}
Rare earth elements (REE) solubility with carbonate salts vary greatly from element to element. The heavy rare earth elements (HRE) being more soluble than the light rare earth elements. Their solubility is a function of the carbonate concentration and the kind of carbonate as sodium, potassium and ammonium. In this work, it is explored the ability of the carbonate for the precipitation of the REE and an easy separation of yttrium was achieved using sodium carbonate to form complex yttrium carbonate followed by oxalic acid precipitation. Form this work REEs concentrate containing (\%) $1.8 \mathrm{Y}_{2} \mathrm{O}_{3}, 1.6 \mathrm{Gd}_{2} \mathrm{O}_{3}, 23.4 \mathrm{CeO}_{2}, 7.6 \mathrm{Nd}_{2} \mathrm{O}_{3}, 11.4 \mathrm{La}_{2} \mathrm{O}_{3}, 2.3 \mathrm{Sm}_{2} \mathrm{O}_{3}, 0.8 \mathrm{Eu}_{2} \mathrm{O}_{3}$ and $3.1 \mathrm{Pr}_{6} \mathrm{O}_{11}$, where the mentioned concentrate was produced after the acid treatment of monazite mineral followed by dissolution with ice water. The produced solution was precipitated with sodium carbonate followed by dissolution in hydrochloric acid and precipitation using oxalic acid to produce yttrium concentrate containing $54.86 \% \mathrm{Y}_{2} \mathrm{O}_{3}$, 15.53\% $\mathrm{CeO}_{2}, 15.29 \% \mathrm{La}_{2} \mathrm{O}_{3}$ and $6.90 \% \mathrm{Nd}_{2} \mathrm{O}_{3}$.
\end{abstract}

\section{Keywords}

Monazite mineral, Yttrium, Homogeneous precipitation, Elemental rare-earths separation.

\section{INTRODUCTION}

Rare earth elements (REE), are increasingly become significant in developing the latest high-tech products, particularly due to their unique properties. REE are found in more than 250 minerals but only three minerals are commercially used for REE extraction mainly bastnasite, monazite and xenotime. Mining and comminution, ore beneficiation through flotation, gravity and magnetic separation and hydrometallurgical processing are the three major routes for REE recovery. In the hydrometallurgical route, the concentrate should initially be digested in order to become soluble in the water or acids. Different methods are applicable in this trend such as acid baking (frequently using $\mathrm{H}_{2} \mathrm{SO}_{4}$ ) and alkaline cracking with $\mathrm{NaOH}$ solution, which are commonly used in the industry scale [Farzaneh Sadri et al; 2017].

Monazite is the main source of REEs in nature [Abreu and Morais; 2010]. Yttrium is always found with rare earth elements in minerals. Rare earth metals are increasingly establishing themselves as crucial industrial materials, with unique applications in numerous fields [Kim and Osseo-Asare; 2012].

Rare earth elements have special properties, so they have a wide range of applications in several high technologies and industries. However, there are many domains for their uses at present which involve metallurgy, catalysis, ceramics and glass, magnets, electronics, optical and medical devices, space instrument and nuclear technologies. 
Rare earth oxides inthe composition of phosphors emitting wave lengths of red,blue and green, so they are mainly used into Cathode RayTubes as in color television screens and color monitors, X-Rayscreens and fluorescent lamps.Yttrium oxide has high melting point, so it was used inadvanced ceramic compounds for special temperatureapplication such as windows for furnaces, microscope lensesand crucibles for vacuummelting of reactive materials like titanium. On the other hand,yttrium oxide is added as sintering agent to Sialon (silicon nitride-based strongest ceramic material). Sialon is used incutting tool tips, adiabatic and turbo-engines as well as acoating on nozzles for high temperature technology.Yttrium is also used in the manufacture of superconductors, in superalloys of nickel and cobalt as well and solid oxide fuelcells. [Sherien H. Ahmed et al; 2014].

A full process for the recovery of rare earth elements from the composite ore containing rare earth elements, including a monazite mineral group and an apatite mineral, contains the pre-leaching of the composite ore with an acid in order to substantially dissolve the apatite mineral into the leach liquor and precipitate rare earth elements from the preleach liquor [Mackowski et al; 2009].

Usually monazite contains about $70 \% \mathrm{RE}_{2} \mathrm{O}_{3}$, and the rare earth fraction is constituted by 20 to $30 \% \mathrm{Ce}_{2} \mathrm{O}_{3} ; 10$ to $40 \% \mathrm{La}_{2} \mathrm{O}_{3}$; significant amounts of neodymium, praseodymium, and samarium; and lesser amounts of dysprosium, erbium, and holmium. Yttrium content may vary from a trace to $\sim 5 \% \mathrm{Y}_{2} \mathrm{O}_{3}$, and thorium content of 4 to $12 \%$ is common. Some amount of uranium is also present in monazite [Doyle, $\mathrm{F}$. M. and Duyvesteyn, S.; 1992].

Various processes have indeed been developed for the individual separation of the REEs from naturally occurring REEs mixtures. Most of these processes depend upon the small differences in their basicity which results from the decrease of their ionic radii from $\mathrm{La}$ to $\mathrm{Lu}$ e.g. less basic hydroxides of the HREE would precipitate before the LREE by gradual alkali addition. Such differences influence in tern the solubilities of salts, the hydrolysis of their ions as well as the formation of complex species. These properties are thus made use of in the various developed separation techniques; namely fractional crystallization, fractional precipitation as well as solvent extraction and ion exchange. Alternatively, it is also possible to make use of the selective oxidation or reduction where certain REEs have a valence state other than the common trivalent oxidation state. In a different case, such elements would exhibit markedly different chemical behavior as compared with their trivalent oxidation state [El-Sheikh, E. M.; 2017].

The heavier lanthanides can be precipitated at lower $\mathrm{pH}$ than the lighter members due to the fact that the decreasing basicity resulting from the lanthanide contraction as the atomic numbers of REE increases. If the $\mathrm{pH}$ is controlled by acid addition, a slight enrichment with respect to the heavier rare earths may be obtained in the precipitated hydrous oxides [Gupta, C. K. et al; 1992].

Precipitation from sulphuric acid leach solutions through acidity control by using a neutralizing agent is the most common promising and economically to separate rare earths constituents initially and considered the least selective precipitation method. This 
method depends on the differences in solubility of rare earth at various $\mathrm{pH}$ values. However, different types of neutralizing agents can be used such as sodium or ammonium hydroxides and calcium or magnesia milk. For large scale operation, ammonia is used for carrying out hydroxide precipitation from the nitrate or chloride solutions [Mostafa M. H. Khalil et al; 2017].

Fractional precipitation is a difficult method utilizing the small difference in basicity between the separate REE. This leads REE to precipitate at different concentrations and/or $\mathrm{pH}$ values when a precipitant is added to a REE solution. A special variant of the method involves melting mixtures of REE nitrates, whereupon the nitrates of the least basic REE will decompose into other, less soluble, salts, allowing subsequent separation by leaching [Hugo Royen and Uwe Fortkamp; 2016].

The main objective of this study is oriented towards the establishment of a simple and inexpensive process for yttrium separation from acidic leach liquor of Egyptian monazite sand (assaying 85\% purity), which obtained as a by-product during the physical separation of black sands to separate the more abundant high economic minerals.

\section{EXPERIMENTAL}

\subsection{Reagents and Solutions}

Unless otherwise stated, all reagents were of analytical reagent grade and all solutions were prepared in calibrated flasks with double distilled water. The experimental work was conducted upon 85\% monazite mineralwas obtained from nuclear materials authority (black sand project), after physical beneficiation of Rashid black sand, Egypt. The $\mathrm{pH}$ of the solutions was readjusted using $0.1 \mathrm{M} / \mathrm{L} \mathrm{H}_{2} \mathrm{SO}_{4}, 0.1 \mathrm{M} / \mathrm{L} \mathrm{NaOH}, 20 \%$ sodium carbonate and $20 \%$ ammonium carbonate.

\subsection{Analytical Procedures}

The most common analytical techniques used to determine yttrium in monazite mineral as gravimetric [Arora, H. C. and Rao, G. N.; 1981], volumetric [Banjeree, G.; 1955], and energy dispersive X-ray fluorescence [Mirashi, N. N. et al; 2010], The total rare earths was determined spectrophotometrically by Arzenazo(III) method [Marczenko; 1986] using the absorption band at $650 \mathrm{~nm}$ on a double beam of high-resolution power UNICAM-UV spectrophotometer.

\subsection{Experimental Procedure}

In this work, the laboratory investigations for the digestion of the Egyptian beach monazite mineral, in order to develop an elaborative direct method to prepare a yttriumcontaining material suitable for purification by fractional precipitation technique using sodium carbonate, ammonium carbonate, oxalic acid, ammonia solution and sodium hydroxide. Separation of the yttrium and rare earth elements precipitates from the monazite sulfate solution, appeared to provide both a direct and an economical method for concentrating the yttrium as a feed material for its further purification. Representative monazite sample (grade $85 \%$ ) was firstly analyzed by XRF to evaluate the existing elements and their concentrations as will be declaredin the results and discussions. The outstanding advantage of the sulphuric acid method is that it can be 
used for all types and grades of commercial monazite and does not require fine grinding [Shinotsuka, K. et al; 1996] [Wayshi, M. M. and Harris, R. E.; 1963].

\subsection{Digestion of Rare Earth, Thorium and Uranium}

Rare earth, uranium, thorium feed solutions for the mini-plant trial were prepared in batches by adding monazite (85 \%) to sulfuric acid at high monazite/acid ratio (1:2.5). In this respect, $250 \mathrm{~g}$ monazite sample was mixed with $625 \mathrm{ml} \mathrm{H}_{2} \mathrm{SO}_{4}$. The mixture was stirred for $2.5 \mathrm{hrs}$ at $200-220^{\circ} \mathrm{C}$, and then diluted with ice water. The slurry was filtrated and the filtrate was diluted with distilled $\mathrm{H}_{2} \mathrm{O}$ to $4000 \mathrm{ml}$ (original solution), and remaining a residue consists of silica, zircon and other undigested gangue materials [Rabie, K. A. et al; 2014].

There are three main reactions occur in the mineral digestion reaction beaker as follows:

$$
\begin{aligned}
2 \mathrm{REPO}_{4}+3 \mathrm{H}_{2} \mathrm{SO}_{4} \longrightarrow(\mathrm{RE})_{2}\left(\mathrm{SO}_{4}\right)_{3}+2 \mathrm{H}_{3} \mathrm{PO}_{4} \\
\mathrm{Th}_{3}\left(\mathrm{PO}_{4}\right)_{4}+6 \mathrm{H}_{2} \mathrm{SO}_{4} \longrightarrow 3 \mathrm{Th}\left(\mathrm{SO}_{4}\right)_{2}+4 \mathrm{H}_{3} \mathrm{PO}_{4} \\
\mathrm{U}_{3}\left(\mathrm{PO}_{4}\right)_{4}+6 \mathrm{H}_{2} \mathrm{SO}_{4} \longrightarrow 3 \mathrm{U}\left(\mathrm{SO}_{4}\right)_{2}+4 \mathrm{H}_{3} \mathrm{PO}_{4} \ldots
\end{aligned}
$$

\section{RESULTS AND DISCUSSIONS}

\subsection{Raw Monazite Sand Composition}

In order to investigate the chemical analysis of the main targeted constituents in the high-grade monazite sand sample (about $85 \%$ monazite) produced during physical beneficiation of Rashid black sand, Egypt [Amira M. Tawfik; 2017], a sample was exposed to X-ray fluorescence analysis. The results of analysis are shown in table 1.

Table (1): The chemicalcomposition of 85\% Egyptian monazite concentrates after acid treatment.

\begin{tabular}{|c|c|c|c||}
\hline Constituent & Percent \% & Constituent & Percent \% \\
\hline $\mathrm{RE}_{2} \mathrm{O}_{3}$ & 52 & $\mathrm{ZrO}_{2}$ & 0.40 \\
\hline $\mathrm{ThO}_{2}$ & 6.04 & Lose of ignition & 11.69 \\
\hline $\mathrm{U}_{3} \mathrm{O}_{8}$ & 0.42 & & \\
\hline $\mathrm{TiO}_{2}$ & 0.38 & & \\
\hline $\mathrm{Fe}_{2} \mathrm{O}_{3}$ & 0.46 & & \\
\hline $\mathrm{P}_{2} \mathrm{O}_{5}$ & 28.61 & & \\
\hline $\mathrm{SiO}_{2}$ & 1.26 & & \\
\hline
\end{tabular}

\subsection{Solubilization Efficiency of Monazite by Sulphuric Acid}

Solubilization of monazite by sulfuric acid process as the classical industrial method, which was determined using two techniques: (1) XRF spectrometry of the solid and (2) by ICP-OES. Cerium was the most abundant of the LREE, followed by lanthanum and neodymium and finished with $1.8 \%$ of yttrium oxide.

The solubility studies was carried out by dissolving 250g monazite containing 52\% $\mathrm{RE}_{2} \mathrm{O}_{3}$ as shown in table 1 in $625 \mathrm{ml}$ concentrated $\mathrm{H}_{2} \mathrm{SO}_{4}$. The concentrate of the rare earth oxides which was tabulated in table 2 . The results shown that the filterate contains 23.4 $\mathrm{CeO}_{2}, 11.4 \mathrm{La}_{2} \mathrm{O}_{3}, 3.1 \mathrm{Pr}_{6} \mathrm{O}_{11}, 7.6 \mathrm{Nd}_{2} \mathrm{O}_{3}, 2.3 \mathrm{Sm}_{2} \mathrm{O}_{3}, 0.8 \mathrm{Eu}_{2} \mathrm{O}_{3}, 1.6 \mathrm{Gd}_{2} \mathrm{O}_{3}$ and 1.8 
$\mathrm{Y}_{2} \mathrm{O}_{3}$. This shown that the concentration of the individual rare earth oxide follows the sequence:

$\mathrm{CeO}_{2}>\mathrm{La}_{2} \mathrm{O}_{3}>\operatorname{Pr}_{6} \mathrm{O}_{11}>\operatorname{Pr}_{6} \mathrm{O}_{11}>\mathrm{Nd}_{2} \mathrm{O}_{3}>\mathrm{Sm}_{2} \mathrm{O}_{3}>\mathrm{Gd}_{2} \mathrm{O}_{3}>\mathrm{Y}_{2} \mathrm{O}_{3}>\mathrm{Eu}_{2} \mathrm{O}_{3}$.

Table (2): Individual REEs concentrations in the monazite concentrate $85 \%$ contain $52 \% \mathrm{RE}_{2} \mathrm{O}_{3}$.

\begin{tabular}{|c|c|}
\hline Element oxide & Concentration [\% (w/w)] \\
\hline $\mathrm{CeO}_{2}$ & 23.4 \\
\hline $\mathrm{La}_{2} \mathrm{O}_{3}$ & 11.4 \\
\hline $\mathrm{Pr}_{6} \mathrm{O}_{11}$ & 3.1 \\
\hline $\mathrm{Nd}_{2} \mathrm{O}_{3}$ & 7.6 \\
\hline $\mathrm{Sm}_{2} \mathrm{O}_{3}$ & 2.3 \\
\hline $\mathrm{Eu}_{2} \mathrm{O}_{3}$ & 0.8 \\
\hline $\mathrm{Gd}_{2} \mathrm{O}_{3}$ & 1.6 \\
\hline $\mathrm{Y}_{2} \mathrm{O}_{3}$ & 1.8 \\
\hline
\end{tabular}

\subsection{Direct Precipitation Using Ammonium Carbonate}

A direct precipitation of thorium, rare earth elements and uranium from the sulfate leach liquor was studied to choose the efficient $\mathrm{pH}$ that precipitates the maximum amount of yttrium usingammonium carbonate solution. Set of experiments were conducted upon $100 \mathrm{ml}$ of the solution at different $\mathrm{pH}$ values $(1.5,2.0,3.5,6.0,7.5$ and addition of $\mathrm{H}_{2} \mathrm{O}_{2}$ as oxidizing agent). The solution was put on $250 \mathrm{ml}$ glass beaker then $20 \%$ ammonium carbonate solution was added gradually till reach the required tested $\mathrm{pH}$. The solution sample was well agitated for one hour at ambient temperature using magnetic stirrer after the $\mathrm{pH}$ adjustment to assure precipitation. After each experiment, the sample was left to decant then the clear solution was separated through filter paper (Whatman 41). The filtrate from each experiment was withdrawn for farther precipitation at higher $\mathrm{pH}$ value from 1.5 to 7.5 andaddition of $\mathrm{H}_{2} \mathrm{O}_{2}$ as mentioned.Each precipitates were ignited and qualitatively analyzed by using ICP and XRF.The results of analysis were shown in table 3.

Table (3): The weight percent of Th, $U$ and the individual rare earth elements at different pHs.

\begin{tabular}{|c|c|c|c|c|c|c|}
\hline \multirow{2}{*}{$\begin{array}{c}\text { Major } \\
\text { Element, }\end{array}$} & \multicolumn{6}{|c|}{ Wt \% } \\
\hline & pH 1.5 & pH 2.0 & pH 3.5 & pH 6.0 & pH 7.5 & $\mathrm{H}_{2} \mathrm{O}_{2}$ \\
\hline Th & 8.92 & 3.13 & 0.75 & 0.64 & ----- & ----- \\
\hline Ce & 14.05 & 33.10 & 31.05 & 25.12 & 21.19 & 15.50 \\
\hline Pr & 1.61 & 4.33 & 2.07 & 2.18 & 1.55 & 0.83 \\
\hline Nd & 5.68 & 14.40 & 10.63 & 10.26 & 5.35 & 6.43 \\
\hline Sm & ----- & ----- & ----- & ----- & 0.55 & 1.01 \\
\hline La & 5.68 & 13.56 & 15.96 & 26.51 & 44.50 & 32.32 \\
\hline Gd & ----- & ----- & ----- & ----- & 2.82 & 3.73 \\
\hline $\mathbf{Y}$ & ----- & ----- & ----- & 9.78 & 14.53 & 9.11 \\
\hline $\mathbf{U}$ & 2.54 & 0.83 & 1.11 & 2.96 & ----- & ----- \\
\hline
\end{tabular}

The efficiency of separation the individual rare earth elements were calculated by using the following equation: 


$$
\text { Precipitation efficiency of REEs, } \%=\frac{\text { Initial REEs Conc. }- \text { Final REEs Conc. }}{\text { Initial REEs Conc. }} \times 100
$$

From the obtained results, the precipitation efficiency for each element were calculated and tabulated in table 4.

Table (4): The precipitation efficiency for $\mathrm{Th}, \mathrm{U}$ and individual rare earth elements.

\begin{tabular}{|c|c|c|c|c|c|c||}
\hline Major & \multicolumn{7}{|c||}{ Precipitation Efficiency \% } \\
\cline { 2 - 7 } Element, & pH 1.5 & pH 2.0 & pH 3.5 & pH 6.0 & pH 7.5 & $\mathbf{H}_{\mathbf{2}} \mathbf{O}_{2}$ \\
\hline Th & 67.83 & 24.95 & 5.17 & 2.05 & ----- & ----- \\
Ce & 15.22 & 37.53 & 30.48 & 11.48 & 3.59 & 1.70 \\
Pr & 17.38 & 48.92 & 20.24 & 9.94 & 2.61 & 0.91 \\
Nd & 15.69 & 41.64 & 26.60 & 11.95 & 2.31 & 1.81 \\
Sm & ----- & ----- & ----- & ---- & 45.45 & 54.55 \\
La & 10.19 & 25.46 & 25.94 & 20.06 & 12.47 & 5.88 \\
Gd & ----- & ----- & ----- & ----- & 53.82 & 46.18 \\
Y & ---- & ----- & ---- & 56.36 & 31.01 & 12.63 \\
U & 44.86 & 15.34 & 17.76 & 22.04 & ----- & ---- \\
\hline \hline
\end{tabular}

From these results, it is clear that the precipitation efficiency of Th, REEs and $U$ different from one to one. For Th precipitation efficiency was about 67.83 which reach at $\mathrm{pH}$ 1.5. By increasing the $\mathrm{pH}$ to 2 value, the precipitation efficiency decreased to $24.95 \%$, the decrease of precipitation efficiency of Th continue to decrease by the increase in $\mathrm{pH}$ value, and become undetected at $\mathrm{pH} 7.5$ and in the presence of $\mathrm{H} 2 \mathrm{O} 2$. This finally means that about 93\% of Th was separate at high acid media $\sim 2 \mathrm{pH}$ values. For the other rare earth elements $\mathrm{Ce}, \mathrm{Pr}$, and $\mathrm{Nd}$, it is observed that the maximum separation occurred at $\mathrm{pH} 2$ and then decreased by increasing the $\mathrm{pH}$ values recording 3.59, 2.61 and $2.31 \%$ at $\mathrm{pH} 7$ respectively. It is found that the separation efficiency for the three elements were 1.7, 0.91 and 1.81in the presence of H2O2. For Sm, it seems that the separation efficiency equal 45.45 at pH 7.5 and equals 54.55 in the presence of $\mathrm{H} 2 \mathrm{O} 2$. For $\mathrm{Gd}$ and $\mathrm{Sm}$, the precipitate by adding ammonium carbonate becomes appeared at $\mathrm{pH} 7.5$ without any appearance of the precipitate in the acidic media. For the $\mathrm{U}$ precipitation efficiency about 44.86 at $\mathrm{pH} 1.5$ and decrease to 15.34 at $\mathrm{pH} 2$, while no precipitate was recorded at $\mathrm{pH}$ 7.5. In the presence of $\mathrm{H} 2 \mathrm{O} 2$, the precipitation efficiency was improved only for Sm and Gd, while its effect on the precipitation efficiency was remarkable for the other elements.From the results, it may conclude that the considerable amounts of Sm separation were occurred at $\mathrm{pH}$ 7.5. On the other hand, La starts to separate at $\mathrm{pH} 1.5$ and decreased to become equal 25.94 at $\mathrm{pH} 3.5$ and then decreased gradually by increasing the $\mathrm{pH}$ till reach to 12.47 at $\mathrm{pH} 7.5$ this may be attributed to dissolve the carbonate at the high $\mathrm{pH}(6-7.5)$.

\subsection{Direct Precipitation Using Sodium Carbonate}

A direct precipitation of thorium, rare earth elements and uranium from the sulfate leach liquor was studied to choose the efficient $\mathrm{pH}$ that precipitating maximum of yttrium usingsodium carbonate solution. Set of experiments were conducted upon $100 \mathrm{ml}$ of the solution at different $\mathrm{pH}$ values $(0.5,1.5,3.0,6.0$, and 9.0$)$. The solution was put on 250 
ml glass beaker then $20 \%$ sodium carbonate solution was added gradually till reach the required tested $\mathrm{pH}$. The solution sample was well agitated for an hour at ambient temperature using magnetic stirrer after the $\mathrm{pH}$ adjustment to assure precipitation. After each experiment, the sample was left to decant then the clear solution separated through filtration using filter paper (Whatman 41). The filtrate from each experiment was withdrawn for farther precipitation at higher $\mathrm{pH}$ value from 0.5 to 9.0 as mentioned.Each precipitates were ignited and qualitatively analyzed against their constituents of the major and rare earth elements were tabulated at table 5 .

Table (5): The weight percent of $T h, U$ and the individual rare earth elements at different pHs.

\begin{tabular}{|c|c|c|c|c|c|}
\hline \multirow{2}{*}{$\begin{array}{c}\text { Major } \\
\text { Element, }\end{array}$} & \multicolumn{5}{|c|}{ Wt \% } \\
\cline { 2 - 6 } Th & pH 0.5 & pH 1.5 & pH 3.0 & pH 6.0 & pH 9.0 \\
\hline Ce & 5.02 & 24.51 & 4.15 & ----- & ----- \\
Pr & 24.73 & 8.56 & 24.31 & 5.65 & 5.89 \\
Nd & 4.83 & 1.56 & 1.85 & 1.23 & 1.03 \\
Sm & 10.39 & 6.23 & 17.39 & 2.64 & 3.66 \\
La & 3.56 & 1.84 & 4.31 & 2.39 & 1.77 \\
Gd & 12.67 & 14.48 & 16.59 & 7.79 & 4.19 \\
Y & 2.33 & 1.33 & ---- & 5.22 & 6.83 \\
U & ----- & ----- & ---- & ----- & 12.53 \\
\hline
\end{tabular}

The precipitation efficiency percent was calculated and tabulated at table 6, which found to reach to $100 \%$ for yttrium at $\mathrm{pH} 9$.

Table (6): The precipitation efficiency for $T h, U$ and individual rare earth elements after sodium carbonate precipitation.

\begin{tabular}{|c|c|c|c|c|c|}
\hline \multirow{2}{*}{$\begin{array}{c}\text { Major } \\
\text { Element, }\end{array}$} & \multicolumn{5}{|c|}{ Precipitation Efficiency \% } \\
\hline & pH 0.5 & pH 1.5 & pH 3.0 & pH 6.0 & pH 9.0 \\
\hline Th & 64.43 & 32.83 & 2.74 & ----- & ----- \\
\hline Ce & 91.03 & 3.34 & 4.69 & 0.66 & 0.29 \\
\hline Pr & 93.92 & 3.18 & 1.89 & 0.75 & 0.26 \\
\hline Nd & 85.97 & 5.41 & 7.54 & 0.69 & 0.39 \\
\hline Sm & 87.34 & 4.73 & 5.53 & 1.84 & 0.56 \\
\hline La & 82.51 & 9.89 & 5.66 & 1.60 & 0.34 \\
\hline Gd & 85.58 & 5.12 & ----- & 6.01 & 3.29 \\
\hline $\mathbf{Y}$ & ----- & ----- & ----- & ----- & 100 \\
\hline $\mathbf{U}$ & ----- & 32.31 & 67.69 & ----- & ----- \\
\hline
\end{tabular}

To study the separation formula of Th, REEs and $U$ by using sodium carbonate solution, a set of experiments were prepared at $\mathrm{pH}$ values from 0.5 to 9. After separation the precipitate was ignited at $750{ }^{\circ} \mathrm{C}$ and exposed to analysis. The results of the analysis 
were shown in table 5. The analysis of the obtained data has shown that: for Th , the maximum efficiency equal 64.43 at $\mathrm{pH} 0.5$ and decreased to the half value 32.83 as the $\mathrm{pH}$ increase to become 1.5. On other hand, the separation efficiency decreased dramatically at $\mathrm{pH}$ equals to 3. At this value the efficiency dropped to record zero value. This means that the most preferable $\mathrm{pH}$ value to separate Th is in the acidic media at law $\mathrm{pH}$.

For Ce, Pr, Nd and Sm, the separation efficiency by using sodium carbonate exhibits maximum values at $\mathrm{pH} 0.5$, whereby increase the $\mathrm{pH}$ value, the precipitation efficiency decreased greatly by increasing $\mathrm{pH}$ values. $\mathrm{Y}$ content separated completely from its solution at basic medium (pH 9). The separation efficiency of $U$ recorded 32.31 at $\mathrm{pH}$ 1.5 and increased to double of this value at $\mathrm{pH} 3$. It is observed that the separation efficiency undetectable at the basic media, this may due to the solubility of $U$ salt in the basic media.

In both direct precipitation experiments, yttrium that considered heavy rare earth elements precipitated at higher $\mathrm{pH}$ value. That may due to the presence of high amount of sulfate which neutralize or react with sodium carbonate and ammonium carbonate forming sodium sulfate and ammonium sulfate. Therefore, we found that this sulfate preferred the precipitation of light rare earths firstly as a double sulfate.

From these results we can apply sodium carbonate precipitation after removal of thorium, uranium and most of light rare earth elements. The produced product was opened by $\mathrm{HCl}$, at which there is some experiments was done at different acids as nitric acid, sulphuric acid and hydrochloric acid. The hydrochloric acid give $98.86 \%$ precipitation efficiency of the rare earth elements while gives 96.85 and $82.73 \%$ precipitation efficiency for nitric acid and sulphuric acid respectively (Mohamed Esmail, 2012). So after dissolution in hydrochloric acid precipitated again by sodium carbonate at final $\mathrm{pH} 3$ in the presence of oxalic acid. The produced precipitate was ignited at $750^{\circ} \mathrm{C}$ for 1 hour to give product with $54.86 \%$ of yttrium oxide as shown in table 7.

Table (7): The concentration of yttrium after dissolution in $\mathrm{HCl}$ followed by precipitation by oxalic acid.

\begin{tabular}{|c|c|}
\hline $\begin{array}{c}\text { Major } \\
\text { Element, }\end{array}$ & Wt \% \\
\hline Ce & 15.53 \\
Nd & 6.90 \\
La & 15.29 \\
Y & 54.86 \\
\hline
\end{tabular}

\section{ConClusion}

The procedure described in this work is very simple, adequate and economical. The monazite mineral was opened by sulfuric acid then dissolute with ice water. The filtered solution can be treated directly with sodium carbonateat $\mathrm{pH}$ between $6.0-9.0$ to obtain $12.53 \%$ of yttrium oxide. This precipitate was purified after dissolute by $\mathrm{HCl}$ and precipitate again at $\mathrm{pH} 3.0$ in the presence of oxalic acid to reach to $54.86 \%$ of $\mathrm{Y}_{2} \mathrm{O}_{3}$. 


\section{REFERENCES}

[1] Abreu, R. D. and Morais, C. A.: "Purification of rare earth elements from monazite sulphuric acid leach liquor and the production of high-purity ceric oxide". Minerals Eng. 23, pp. 536-540, (2010).

[2] Tawfik, A. M.: "Waste management of Egyptian monazite processing". Ph. D. thesis, Faculty of science, Ain Shams University, Egypt, (2017).

[3] Arora, H. C. and Rao, G. N.: "Gravimetric determination of uranium (VI) and thorium (IV) with substituted pyrazolones". Indian J. Chem. A 20, 20(5), pp. 539540, (1981).

[4] Banjeree, G.: "Rapid titrimetric determination of thorium with fluoride using SPADNS". Fresen. Zeit. Anal. Chem., 146(6), pp. 417-422, (1955).

[5] El-Sheikh, E. M.: "Selective recovery of yttrium and ytterbium oxides from Abu rusheid rees concentrate via alkaline leaching and solvent extraction". Arab journal of nuclear science and applications, 50 (2), pp. 67-78, (2017).

[6] Doyle, F. M. and Duyvesteyn, S.: "Aqueous processing of minerals, metals and materials". JOM, 45 (4), pp. 46-54, (1992).

[7] Sadri, F.; Nazari, A. M. and Ghahreman, A.: "A review on the cracking, baking and leaching processes of rare earth element concentrates", Journal of rare earths, vol. 35, No. 8, p. 739, (2017).

[8] Gupta, C. K. and Krishnamurthy, N.: "Extractive metallurgy of rare earths". International materials reviews, 37, No. 5, pp. 204-16, (1992).

[9] Gupta, C. K. and Krishnamurthy, N. K.: "Extractive metallurgy of rare earth's". International materials review. vol. 37, No. 5, p. 197, (1992).

[10] Royen, H. and Fortkamp, U.: Report C 211 - "Rare Earth Elements - Purification, Separation and Recycling". IVL Swedish environmental research institute, (2016).

[11] Rabie, K. A.; Abdel-Moneam, Y. K.; Abdel-Fatah, A. I.; Demerdash, M. and Salem, A. R.: "Adaptation of anion exchange process to decontaminate monazite rare earth group from its uranium content". International journal of research in engineering and technology, vol. 03, Issue 06, pp. 374-382, Jun. (2014).

[12] Kim, E. and Osseo-Asare, K.: "Aqueous stability of thorium and rare earth elements in monazite hydrometallurgy". Hydrometallurgy, 113-114, pp. 67-78, (2012).

[13] Mackowski, S. J. et al.: "Recovery of rare earth elements". US patent 0272230 A1, (2009).

[14] Marczenko: "Spectrophotometric determination of elements". John Wiley and sons Inc. New York, (1986).

[15] Mirashi, N. N.; Dhara, S.; Kumar, S. S.; Chaudhury, S.; Misra, N. L. and Aggarwal, S. K.: "Energy dispersive $\mathrm{x}$-ray fluorescence determination of thorium in phosphoric acid solutions". Spectrochim. Acta B: Atom. Spect., 65 (7), pp. 579-582, (2010).

[16] El-Awady, M. E. M.: "Recovery of rare earth elements as by-product from gattar (v) mineralization". M. Sc. thesis, Faculty of science, Benha University, Egypt, (2012).

[17] Khalil, M. M. H.; Rabi, K. A.; Atrees, M. S.; Abdel-Fatah, A. I. L.; Demerdash, M. and Roshdi, R.: "Development of thorium separation, upgrading and purification processes for its pre-conceptual high grade production from crude monazite mineral". ISOTOPE \& RAD. RES., 49 (1), pp. 123-137, (2017).

[18] Ahmed, Sh. H.; Helaly, O. S. and Abdel-Ghany, M. S.: "Preliminary study for separation of heavy rare earth concentrates from Egyptian crude monazite". World academy of science, engineering and technology, International journal of materials and metallurgical engineering, vol. 8, No. 8, (2014). 
[19] Shinotsuka, K.; Hidaka, H.; Ebihara, M. and Nakahara, H.: "ICP-MS analysis of geological standard rocks for yttrium, lanthanides, thorium and uranium". Anal. sci., 12 (6), p. 917, (1996).

[20] Wayshi, M. M. and Harris, R. E.: "Rare earth elements" In: Kolthoff, I. M. and Elving, P. (Eds.), Treatise on analytical chem. Part II. Analytical chem. of the elements, vol. 8. Wiley, New York, p. 21, (1963). 